\title{
An Extensive Design Approach Integrating Offshore Residential Buildings and Solar Collectors
}

\author{
Ruozhu Wang ${ }^{1}$, Ruting $\mathrm{Ma}^{1}$, Guang Hong ${ }^{2}$, Wei Tian ${ }^{1}$, Yongmei Qian ${ }^{1 *}$ \\ ${ }^{1}$ Jili Jianzhu University, Changchun 130118, China \\ ${ }^{2}$ Northeast Electric Power Design Institute Co., Ltd of China Power Engineering Consulting Group, Changchun 130118, China
}

Corresponding Author Email: qianyongmei@jlju.edu.cn

https://doi.org/10.18280/ijht.390517

Received: 10 June 2021

Accepted: 25 August 2021

\section{Keywords:}

integration, offshore residential building, solar energy, solar collector, extensive design approach

\begin{abstract}
Utilization of energy has boosted socio-economic development but meanwhile exacerbated the environmental problems. Offshore areas in China boast abundant solar energy resources. The present work explores the application of solar energy in offshore residential buildings and the ways for integration of solar collectors with the buildings to analyze the potential impact of installation of solar collectors on the design of offshore residential buildings. An extensive design approach that introduces protruding features, outdoor airconditioner unit spaces, and "virtual" elements into design of residential buildings was proposed, which would integrate the solar collectors into the architectural design and extend the functions of the residential buildings. This research aims to provide a theoretical basis for promoting utilization of solar energy and integrated design of offshore buildings.
\end{abstract}

\section{INTRODUCTION}

With the economic development, the energy demand tends to grow constantly. The energy utilization brings faster socioeconomic development but meanwhile exaggerates the environmental problems. Nowadays, energy and environmental issues draw increasing attention, but traditional gas and electric water heaters have caused a great many environmental problems including high energy consumption, waste gas pollution, and safety issues, forcing people to look at renewable energies with great prospects for development [1].

China has a vast land area and a tremendous reserve of solar energy because two-thirds of the national land has an annual radiation output of about $6,000 \mathrm{MJ} / \mathrm{m}^{2}$. Offshore areas boast rather rich solar resources, with the annual radiation output topping 4,500 $\mathrm{MJ} / \mathrm{m}^{2}$. Although solar energy is so abundant, most of its utilization in China's residential buildings remains passive, and active solar houses are still in their infancy [2].

Since the beginning of the new century, offshore areas have stressed the importance and promoted the application of solar water heaters [3]. Over the years, more and more solar water heaters have been installed on building roofs; however, due to the lack of unified planning [4], most of these heaters are dislocated, with pipelines arranged in a messy and less artistic manner; In this context, therefore, it has become a hot research topic to achieve the aesthetic integration between solar heaters and architectural appearance without compromising the functionality of solar equipment [5].

At this point, the focus of aesthetic design are the architectural expressions that allow the integration of solar collectors and other design components into residential buildings [6]. In addition to functionality and efficiency, the design also seeks to fulfill such functions as protection, thermal insulation, shading, and exterior design of the building. Considering the color, texture, material, and other characteristics of solar collectors, the proposed approach aims to take the solar collectors as an integral element of the exterior design of residential buildings [7]. From the perspective of aesthetics, three integration methods, namely, extension, transformation, and substitution, are proposed. Among the three methods, the research focuses on the extension design method, which introduces protruding features, outdoor airconditioner unit spaces, and "virtual" elements into design of residential buildings, so that solar collectors can break the original boring layout, highlight protruding elements on the facade, and be perfectly integrated into the architectural design.

\section{EXTENSIVE DESIGN APPROACH}

To extend is to lengthen or stretch outward in width, size, and scope. Extension can be applied to both physical objects and abstract topics [8]. The extensive design approach means to extend or reproduce an element. "Extension" design is a common practice in architectural design, for design of components and details of overall planning and exterior appearances.

The height and size of modern buildings, especially highrise buildings, limit the natural ventilation, which makes mechanical ventilation and air supply a necessity, and as a result, more and more equipment rooms appear on the roofing of modern buildings [9]. Facing these challenges, architects tactfully extend the glass curtain wall to achieve a shading effect on the roof, improving the exterior design effect of the building without compromising the original layout (Figure 1).

Solar collectors are a kind of new component that can be integrated into the design of residential buildings to create a new sense of order and rhythm with other components. Introduction of this element not only makes the original orientation more salient, but adds a new speck of vigor to the once anodyne design pattern. The following sections will introduce the extension approach that integrates solar 
collectors with residential buildings.

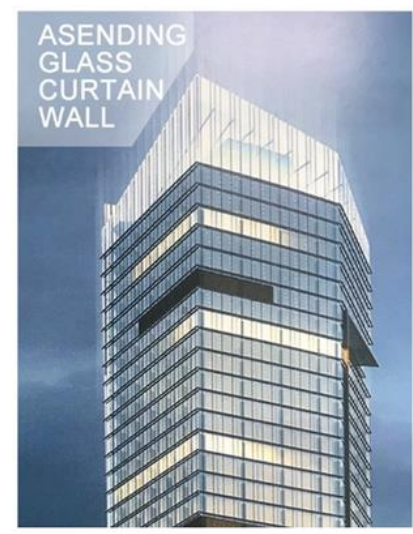

Figure 1. Buildings with ascending glass curtain walls

\subsection{Extension as a protruding element}

Besides the practical functions, architects of modern residences pay more and more attention to the expression of the internal space to create an external shape with concavity and convexity [10]. In this case, such components as balconies, bay windows, and outdoor AC unit spaces become active elements, playing a key role in diversifying the building façade and creating nuances of gradations. In particular, when these components appear recurrently on each floor of a residential building, a vertically ascending pattern is formed. (Figure 2).

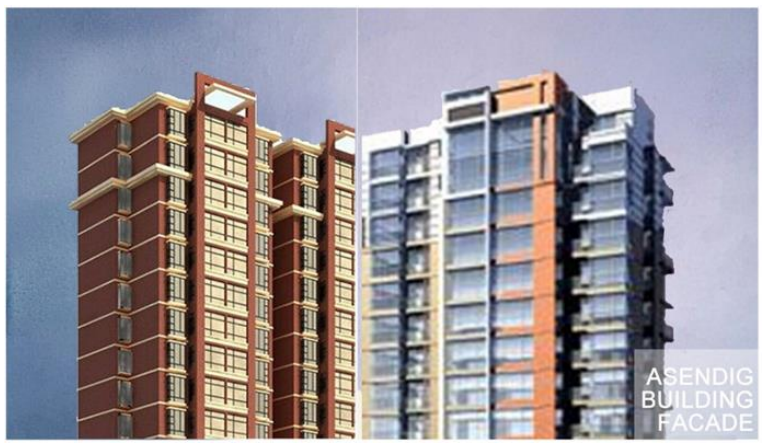

Figure 2. Building facades with an ascending tendency

This ascending pattern often breaks at the roof, where there are bare stairs and equipment rooms. To solve this issue, the solar collectors can be installed as an integral part of the residential building so that the balconies and bay windows keep an upward pattern and the whole building can maintain an ascending pattern. Meanwhile, the dark black and bule texture of solar collectors forms a "virtual" element which makes a smooth transition of color from the building to the sky, so that it feels like the building fades gradually to the sky instead of being a stark contrast to the blue sky. In northern China where the thermal insulation is poor in residential houses, the bay windows are less protruding than those in southern China, and thus only the architects need only to consider the integration between balconies and solar collectors and overlook the ascending pattern of the building.

The practice is to install solar collectors on both the sill walls of balconies and the parapet walls on the top of balconies, which in essence supplies hot water to lower-floor users. Both two solar collector types are acceptable: the flat-plate solar collector has a good overall effect, and the vacuum tube solar collector has a good hiding effect. When the solar collectors are installed to the building, brackets pre-adjusted to a certain angle are fixed to the components pre-embedded into the parapet walls. In a coastal region at a latitude of $43.40^{\circ}$, the optimal inclination angle of the solar collector is $43.40^{\circ}+10^{\circ}=53.40^{\circ}[11]$. This optimal inclination angle may differ from the aesthetically optimal angle, and in the case of flat-plate solar collectors, the compensation area must be calculated based on the obtained data, to meet the users' requirements for hot water use [12]. Both methods are conventional construction practices, and besides thermal insulation and roofing flashing, there are no special requirements. Details of these two installing schemes are shown in Figures 3 and 4.

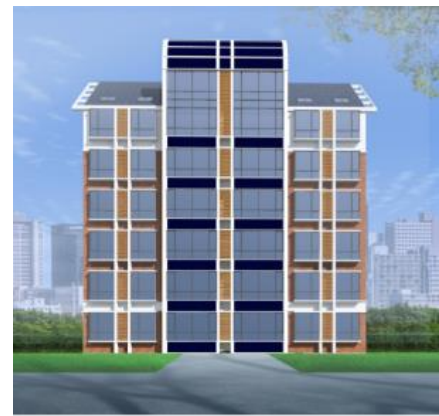

Figure 3. Profile of the extensive design of protruding components

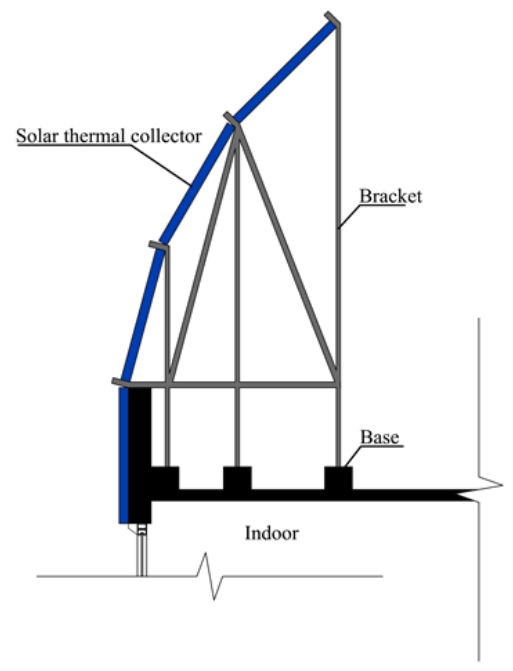

Figure 4. Diagrammatic cross-section through the extensive design of protruding components

Different from residential buildings where no solar collectors are installed or the collectors are installed on the sill walls of balconies only, those installed with solar collectors show smoother transition from the roof and the sky without compromising the original shape and style. In this case, the solar collector acts as a "virtual" element that facilitates the transition (Figures 5). These solar collectors not only extend the original architectural style of the residential building and enrich the structure of the building roof, but also add new zest to the original structure and continue the ascending tendency of the building. Moreover, the arc shape of the collectors that generates a touch of novelty and flexibility forms a stark contrast to upright and square-shaped building that exudes an air of prudence. 
CONCEPT SKETCHES AND MODEL

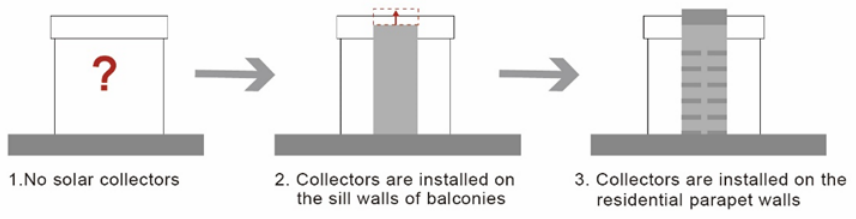

Figure 5. Layout of protruding elements on the facade

The extension-based integration between solar collectors and the residential parapet walls boasts many advantages. For instance, it enhances the original ascending tendency of the buildings, smoothens the transition between the building and the sky, and strengthens instead of compromising the original pattern and rhythm of the residential building. Thus, the solar collector not only fulfills its own functions, but contributes to the aesthetic value of the building. Such integration makes the solar collector an integral part of the residential building, a design component, and a design language.

\subsection{Extension of outdoor air conditioner unit installation space}

When air conditioners first appeared in China in the 1980s, they were considered as exorbitant luxuries unaffordable for most consumers. The resulting extremely low demand stemmed the development of the air conditioning industry. As the per capita income grew in the 1990s, air conditioners became affordable for more consumers and began to play an important role for cooling in summers and heating in winters, especially in southern China. Nonetheless, due to the high price and maintenance fee, air conditioners at that time were mainly used in developed southern cities. Upon the arrival of the new century, the air conditioning industry developed to a new height, with the cooling and warming techniques considerably improved, and the price of air conditioners substantially reduced to a level affordable by most consumers. Consequently, air conditioners become a routine household appliance like TVs and washing machines in families in southern China and a regular device in industrial plants and office buildings in northern China.

Over forty years, air conditioners have developed from an unaffordable luxury in the 1980s to a fundamental piece of house appliances now in China. In design of buildings, the architects will factor in the arrangement of the outdoor AC unit installation space into the overall planning, considering the practical functions of the air conditioner and its impact on the shape of the building. In particular, a uniform arrangement of $\mathrm{AC}$ units in residential buildings will enhance the sense of rhythm and improve the aesthetic value of the building. (Figures 6 and 7).

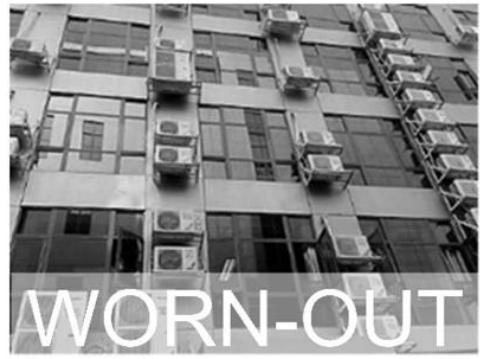

Figure 6. Non-uniform outdoor AC unit arrangement

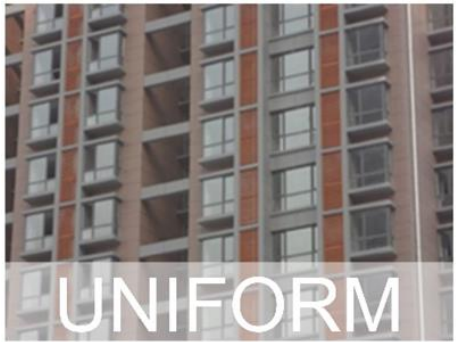

Figure 7. Uniform outdoor AC unit arrangement

The integration between outdoor AC unit arrangement and residential buildings sets a good model for the integration between solar water heaters and buildings. Thirty years ago, few would imagine that the air conditioner would be so useful that architects in the future would reserve a space specifically for it in building design and consider its impact on the appearance of the building. Thirty years ago, most residential buildings had a flat façade, without bay windows or an installation space for $\mathrm{AC}$ units; the balconies were flush with the outer surfaces of the building, so households would have to fabricate a bracket themselves to install an outdoor $\mathrm{AC}$ unit, which was neither attractive nor tidy. Installation of solar water heaters today is in the same situation as that of air conditioners thirty years ago: most households have to install brackets outside their apartment for the solar water heater, making the heater a blight to the original view. Fortunately, as architects are increasingly aware of the practical and environmental value of the solar water heaters and solar heating becomes a popular way for hot water supply among households in China, architects begin to factor in the installation of solar collectors into the overall building design. Specifically, they will decide on the type of the solar collectors, calculate the optimal angle for installation and avoid unnecessary shading over the lower floors when designing the space for the solar collectors along the wall and on the roof of the building [13]. This practice only aims to install the solar collectors, but does not factor in the impact of the installation of the solar collectors on the shape, texture and rhythm of the original building. As a result, the aesthetic value is largely overlooked though the solar collectors are installed in a uniform and tidy manner [14]. Design of the outdoor AC unit installation space has already become mature, but how to integrate the installation of solar collectors to the original structure of the building remains a challenge, which is to be detailed in the following section.

The air-conditioner installation spaces that face south are generally arranged between two windows so that it can be used for two adjacent rooms. In modern buildings, outdoor AC units are often covered by louver screens, which can protect the units from erosion by rain or snow and conceal the varied colors, sizes and models of the different brands of units to present a uniform view outward. If the louver screens stretch upward and downward to the AC installation space on each floor, an ascending line will be formed; therefore, the integrated design of solar collectors and outdoor AC unit spaces must produce a unified texture. Vacuum tube solar collectors have a similar texture with louver screens. At the beginning of residential building design, equipment manufacturers and architects can coordinate the texture modulus between the louver screens and solar collectors to an acceptable extent, to ensure the same density. As the color of the solar collectors should be dark blue to achieve the optimal heating effect, the louver screens for AC installation spaces 
should also be designed into dark blue to ensure consistency. Besides integration with the $\mathrm{AC}$ installation space, the installation space for solar collectors should show its own features. For instance, lighter-colored frame lines can be designed to define the borders of the installation space with that for other devices, so that the installation space of solar collectors conforms to the overall pattern of the building but meanwhile shows its own features, forming a good mastercoordinate relationship with the building (Figure 8).

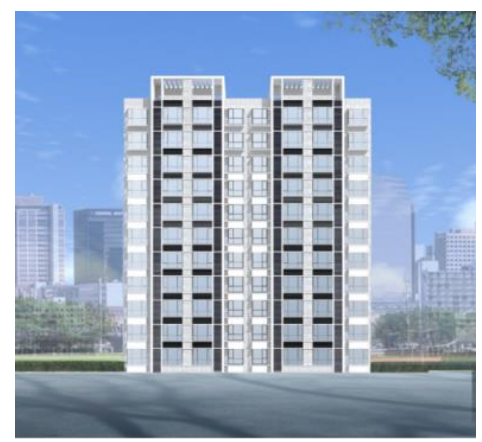

Figure 8. Rendering of extensive design of solar collectors

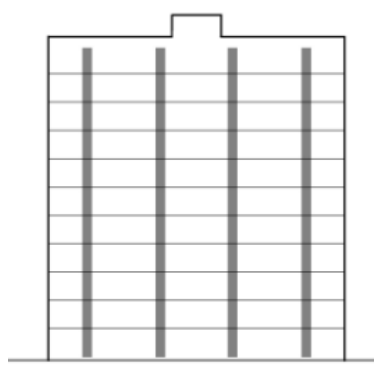

Figure 9. Before installing solar water collectors (boring)

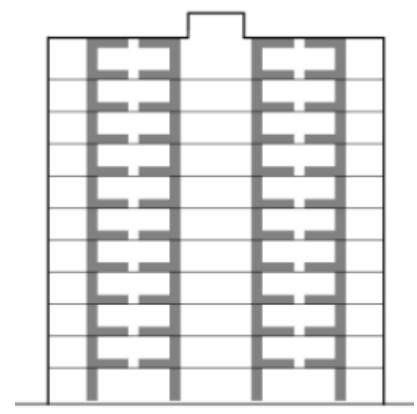

Figure 10. After installing solar water collectors (active)

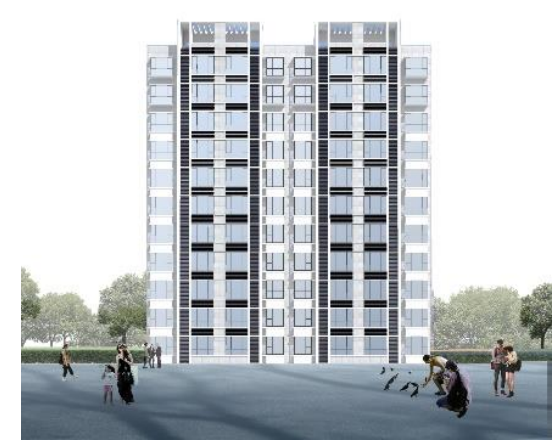

Figure 11. After installing solar water collectors (active)
The specific practice is to install the solar collectors close to the outdoor AC unit installation space on the walls under the bedroom or balcony windows. Figure 9 shows the installation scheme where the solar collectors are mounted on the wall. As the vacuum tube solar collectors are used, there is no need to consider the compensation area and other issues. Water tanks then can be arranged in the bedroom or on the balcony (Figures 10 and 11) to reduce the heat loss of the solar collectors and improve the utilization efficiency of hot water. For arrangement of the pipelines, it is preferrable to conceal the pipes and wires in the ceilings to facilitate installation and maintenance.

The designed solar collectors form an extension of the outdoor AC unit installation space, which add new zest to the humdrum pattern of vertical lines along the façade of the building. The integration between solar collectors and the outdoor AC unit installation space will enliven the southern façade of the building, which is more prominent in symmetric buildings as the integration will produce a centripetal pattern.

Integration between the solar collectors and the outdoor $\mathrm{AC}$ unit installation space features collision between two design elements: the solar collectors, as a "new comer" to the architectural design, can be fully integrated into the outdoor AC unit installation schemes, making a break to the original humdrum structure and enliven the façade of the building. As long as there is a grid-pattern AC unit installation space on the southern façade of the building, such integration can be realized, regardless of the story, elevation, and style of the building.

\subsection{Horizontal extension of "Virtual" elements}

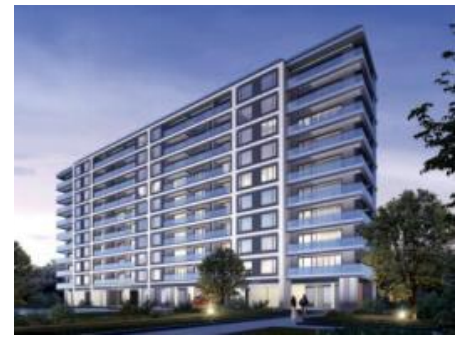

a. Architecture style with more virtual element and a sense of lightness

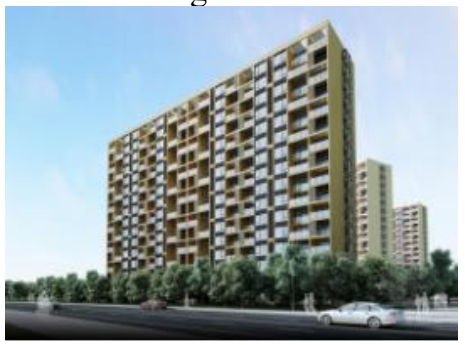

b. Architecture style with proper virtual and real elements

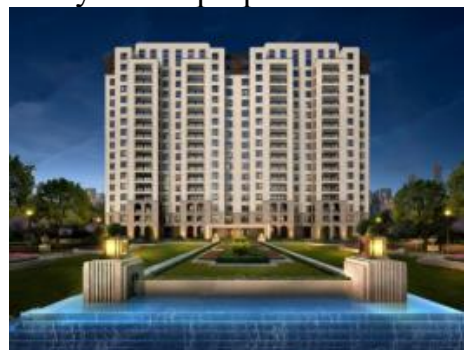

c. Solemn architecture style with more real elements

Figure 12. Influence of virtual-real proportion on volume of residential buildings 
In exterior design of buildings, such components as walls and columns are regarded as "real" elements; while other elements like windows and louvers are considered as "virtual" elements. A proper combination of these two types of elements can enhance the aesthetic value of the building. Buildings loaded with too many "real" elements will look bulky, while those with excessive "virtual" elements will appear frivolous. It is necessary to strike a balance between these two types of elements in architectural design.

For design of green homes, different design styles lead to varied appearances of the building. As neomodern and ultramodern architectural design values transparency in space and appearance, it has many virtual elements and a sense of lightness (Figure 12). The European style of architectural design which focuses on the vertically ascending tendency emphasizes the design of the bottom columns to present a solemn sense. Other styles between the foresaid two styles are conventional [15].

Restricted by the interior room layout, residential buildings have no extra windows. To strike a balance between shading and thermal insulation, it is hard to enlarge the window openings. Therefore, even though windows are arranged on the largest south façade, it is still difficult to achieve a windowwall ratio of $1: 1$. Moreover, there are many repetitive elements in the residential buildings, which makes the inflexible façade more unwieldy. Solar collectors with a dark-blue texture will form a "virtual" element when combined with the wall, which fills in the gap of "virtual" window element to achieve the balance between virtual and real elements and becomes a horizontal extension of virtual elements.

The specific practice is to install solar collectors on the outer wall of the bedroom between two households. Solar collectors are fixed to the embedded poles and inclined outward by a certain angle. As this angle may not be the optimal inclination angle, area compensation is required for these solar collectors. Figures 13 and 14 show the influence of solar collectors on the south façade appearance of a residential building.

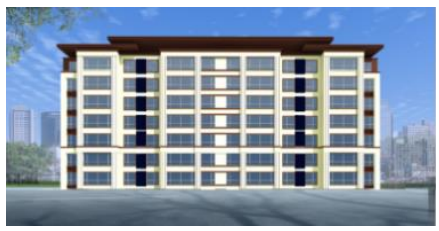

Figure 13. Solar collectors before coordinated design

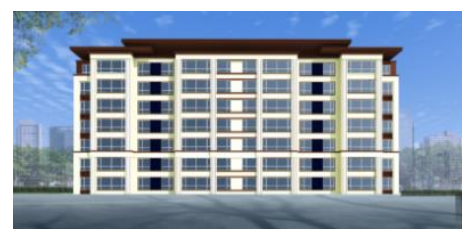

Figure 14. Solar collectors after coordinated design

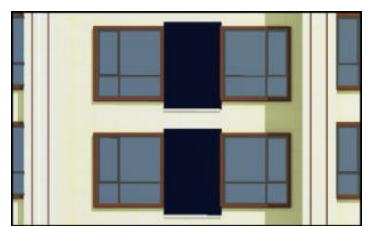

Figure 15. Architraves between windows and solar collectors before installation

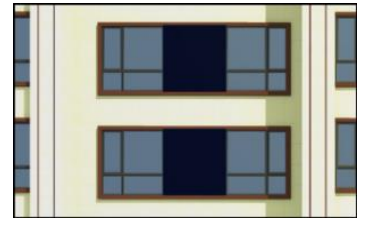

Figure 16. Architraves between windows and solar collectors after installation

1) Organic integration: When solar collectors are integrated with windows (Figure 15), their size and modulus do not match these windows, which leads to stiff transitions between solar collectors and windows. Moreover, the architraves (window frames) at the windows exclude the solar collectors instead of encasing them. Through organic integration design, the solar collectors will interact with windows more harmoniously (Figure 16). An integrated whole is formed together with two adjacent windows surrounded by an architrave. Solar collectors are closely connected with windows, with boundaries delineated by lighter-color frames, which generates slight changes among a unified context and a master-coordinate relation.

2) Rhythm enhancement: Due to its size, the solar collector cannot be directly integrated into the original pattern. As shown in Figure 17 a, virtual elements are in a rhythm of 1-2$1,1-2-1,1-2-1,1-2-1$. These short and boring patterns are repeated so much that they give a perfunctory sense, which is not recommended in architectural design. After design, the rhythm is enhanced into $1-2-2-2-1,1-2-2-2-1, \ldots$ with less repetitions but richer layers in each unit, and the modulus "three" is introduced to the rhythm. "Three" is a special numeral in Chinese: it can indicate the specific number of three, and also serves as a metaphor of infinity, which will enrich the rhythm of the architecture.

Arrangement of Virtual Elements

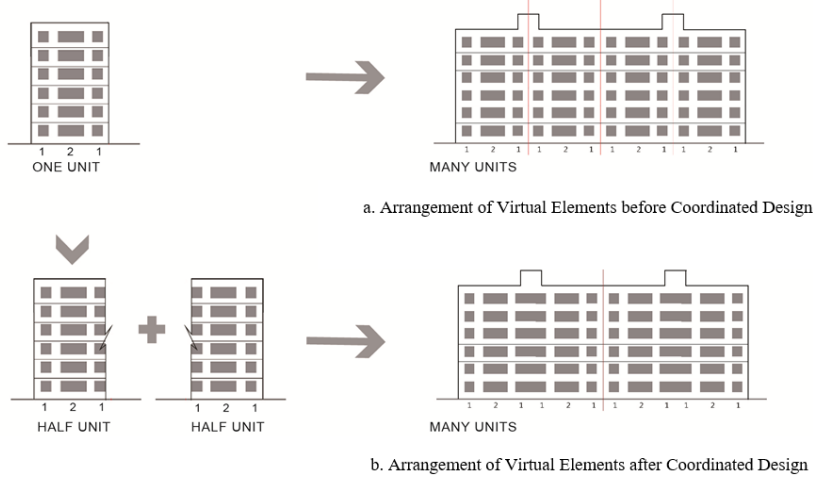

Figure 17. a. Arrangement of virtual elements before coordinated design; b. arrangement of virtual elements after coordinated design

3) Highlighted central axis: Figure $17 \mathrm{~b}$ shows many axes of a building: one central axis and two symmetry axes on the left and right sides each. This weakens the position of the central axis and makes the center shift. After design, because windows are connected with solar collectors, they are different from the windows in the middle; therefore, the symmetrical axes (as shown in Figure $17 \mathrm{~b}$ ) are weakened and the central axis is enhanced, making the sketch of the residential building more concise, with the center highlighted. 
As a virtual element integrated with walls between residential windows, the solar collectors are fully incorporated into the building, which forms an organic whole with the windows, enhances the original rhythm, enriches individual units, weakens the secondary symmetry axes, and improves the construction pattern. This practice is applicable to residential buildings with different floors, especially for those with two elevators and four apartments on each floor.

\subsection{Vertical extension of "Virtual" elements}

The following section describes the vertical extension of virtual elements. Bay windows in modern buildings first appeared in the early $20^{\text {th }}$ century, mainly in high-end residential buildings like villas. In the $21^{\text {st }}$ century, limited by availability of land, and due to the provisions released by the Ministry of Construction that bay windows not higher than 2.1 $\mathrm{m}$ should not be included into the sales area, bay windows become more and more widely applied in residential buildings. Bay windows appear not only in large spaces such as living rooms and bedrooms, but also in small spaces such as study rooms and toilets. Their orientation also changes: the windows no longer just face south, and in southern cities, many northfacing windows have been designed.

Due to the special climate conditions in Northeast China, the bay windows can be designed only for south-facing apartments. Though the increase in the shape coefficient leads to a heat loss, high quality thermal-insulation materials can maintain a comfortable temperature in the room $[16,17]$. Now the common method of bay window construction is to elevate a $600-900 \mathrm{~mm}$ lift from the floor level, stretching upward to be flush with the window lintel, protruding outward to form a bay to an extent depending on local climate conditions. The colder the region is, the less protruding the bay window is. For example, in Northeast China, the bay windows can only be protruded for 400-600 mm. This will form a gap of at least 900 $\mathrm{mm}$ between two bay windows. From the perspective of aesthetics, it enriches the elevation shapes and improves the light and shadow effect. However, this light and shadow effect exaggerates the sense of difference and extends the distance between human beings and buildings. To sum up, though the shadow effect is important, the resulting sense of difference weakens the atmosphere of the building as a "home", turning the building into a cold product of the industrial age. Luckily, with the integration between solar collectors and bay windows, this situation will be greatly improved.

For different types of solar collectors, the integration methods differ as well. As the vacuum tube solar collector does not need any area compensation, it can be directly placed between two bay windows; in the case of flat-plate solar collectors, however, the optimal installation angle should be identified and the area of compensation should be calculated. Installation of different types of solar collectors will result in different textures and patterns of the building.

1) Vacuum tube solar collectors: without specific requirements for the inclination angle, this type of solar collector can either stay inclined or stand upright. In order to reduce shading of the collectors to the lower floor, these solar collectors are vertically integrated into the building. To this end, the size of the solar collector and the window should match. The width of the solar collectors should be calculated as per the length of the window to decide the spacing between two bay windows; and a base is set between two bay windows and is connected to the solar collector by pre-embedded poles
(Figure 18).

Seen from the outside, the screen-type vacuum tube solar collectors form a semi-virtual element, which establish a transition to the virtual window element, and make up the sense of difference between bay windows. This integration scheme is appliable to residential buildings with bay windows. The integration effect will be enhanced if more decorative components are arranged [18].

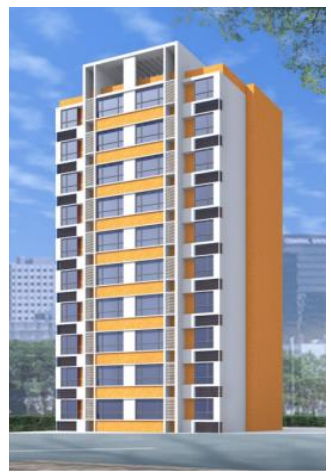

Figure 18. Rendering of vacuum tube solar collectors under bay windows

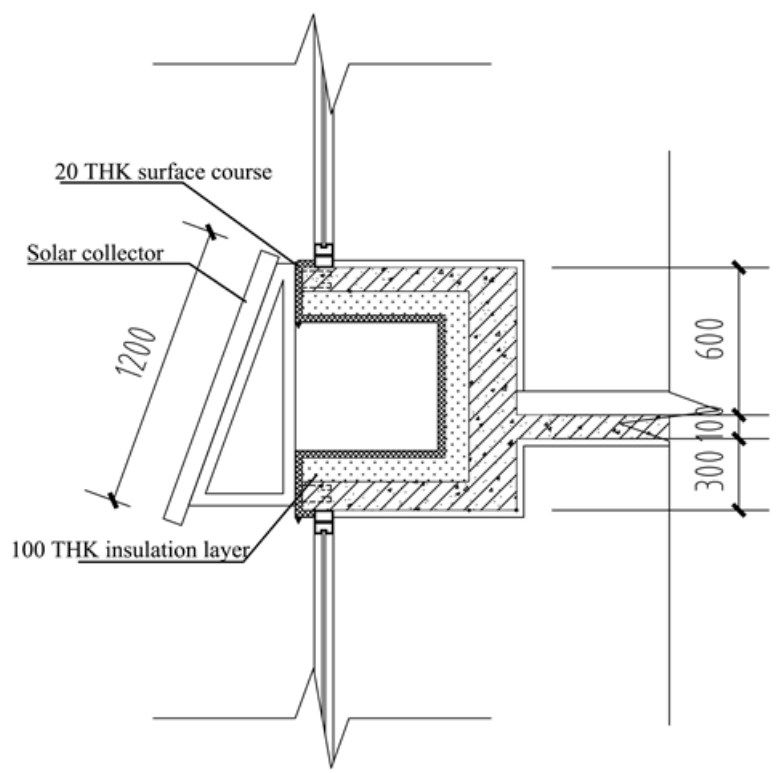

Figure 19. Construction diagram of solar collector arranged between bay windows

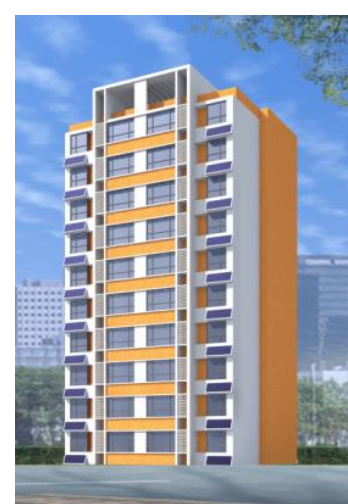

Figure 20. Rendering of flat-plate solar collectors under bay windows 
2) Flat-plate solar collectors: This type of solar collector has more complex features, because their inclination angles must be adjusted during installation to achieve the maximum thermal concentration efficiency (Figure 19). The optimal inclination angle is $43-53^{\circ}$ in some offshore areas mentioned above; in this case, their area will be $1.96 \mathrm{~m}^{2}$ to meet the demands of each household. However, this inclination angle leads to an excessive shadow of projection that will shade the lower floor. To increase the inclination angle could help solve this problem. Specifically, we can change the installation area of the solar collector and increase the length of the solar collector, so that the solar collector will not affect the lighting of the lower floors while improve the heating efficiency. Besides, the extended solar collectors can fit better with other building components without compromising the original pattern and rhythm of the building (Figure 20).

No matter which integration scheme is adopted, water storage tanks can be arranged in bedrooms or balconies to reduce the heat loss of solar collectors and improve the utilization efficiency of hot water. Pipelines are preferably concealed in ceilings to facilitate installation and maintenance.

Compared with the cases where no solar collectors are installed or the solar collectors are installed in an unorganized manner to the buildings, the integration design method extremely enhances the vertical line and highlights the ascending tendency of the building [5]. In particular, for excessively high plate buildings, the integration design scheme strengthens the vertical and horizontal partitioning, and makes the buildings less unwieldy. This method is applicable to most residential buildings with south-facing bay windows. For residential buildings with an excessive heightlength ratio, it highlights the ascending nature; while for those with tool small height-length ratio, it enhances the partitions and makes the structure lighter.

The integration design method, however, also suffer defects. The inclined flat-plate solar collectors will shade the sunlight to the lower floor, so this type of solar collector is not suitable for residential buildings short of sunlight, but is only applicable to south-facing buildings or residences with large spacings in between.

\section{CONCLUSION}

Upon the analysis of current situations, a design approach that integrates the solar collectors to residential buildings in offshore areas is proposed [19]. Meanwhile, as per the characteristics of the residential building, the integration methods and features of the extension design approach, or the extension-based integration design scheme are analyzed. The details are as follows. The solar collectors are integrated into residential buildings as an extensive element to create a new sense of order and rhythm with other components of the building. This not only strengthens the original sense of order of the building and makes it more attractive, but also adds new zest to the original boring structure. The impact of the integration scheme is analyzed, the locations of solar collectors and water storage tanks as well as the arrangement of pipelines are explored to ensure that the solar collectors can fulfill their functions safely and efficiently. Meanwhile, with the application of new solar water heaters built in the windows, new products are developed, which make solar water heaters an integral part of the building and a design language of the residential building.
Utilization of energy accelerates social development, but meanwhile leads to environmental problems. The coaldominated energy consumption structure produces lots of pollutants that has considerably degraded the environment in China.

Therefore, from the start of the $12^{\text {th }}$ Five-year Plan, the solar energy industry has been growing at an annual rate of about $30 \%$ in China. Solar water heaters are widely adopted in cities. From the perspective of long-term development of organic integration of solar energy to residential buildings, few solar water heaters have been reasonably integrated into buildings for the time being, and modular design of such integration is yet to be improved. To promote the integration between the solar water heating systems and residential buildings, China has successively issued policies and specifications, and made continuous efforts to truly realize the integration between the solar energy and buildings.

Given there are abundant solar energy resources in offshore areas, the research findings here are expected to support for effective utilization of solar energy in offshore residential buildings. Plus, as the previous construction method is adopted, it enjoys high feasibility. The synchronous design and construction of solar water heater and offshore residential buildings make the two perfectly coordinated, which finally render solar water heater an important future direction of renewable energy application technology.

\section{ACKNOWLEDGMENT}

This research is funded by National Natural Science Foundation of China (Grant No.: 52078239, 51478205).

\section{REFERENCES}

[1] Xue, Y.B., Yang, Q.M., Wang, C.J. (2014). Building Solar Energy Utilization Technology for Series Teaching Materials of Building Environment and Energy Application Engineering in General Colleges and Universities. China Building Materials Press.

[2] Wang, R., Qian, Y., Tian, W., Jiang, X. (2020). Integration between energy-saving solar heating equipment and high-rise residential buildings. Journal of Environmental Protection and Ecology, 21(5): 16971707.

[3] Xue, H.S. (2016). Experimental investigation of a domestic solar water heater with solar collector coupled phase-change energy storage. Renewable Energy, 86: 257-261. https://doi.org/10.1016/j.renene.2015.08.017

[4] Chen, H., Sui, Y.B., Zhao, J.L. (2020). Research on sustainable development of green building. Journal of Environmental Protection and Ecology, 21(2): 561-570.

[5] Murmu R., Kumar P., Singh H.N. (2018). Experimental investigation on heat transfer and friction factor for an inclined spherical ball roughened solar air heater, Instrumentation Mesure Métrologie, 17(1): 7-36. https://doi.org/10.3166/I2M.17.7-36

[6] Wang, R.Z., Qian, Y.M., Wang, T.H. (2011). Analysis on the integral combination on building and solar water heater in the real project design of residential building at the north-east district. Journal of Jilin Institute of Architectural and Civil, 28(1): 55-58. https://doi.org/10.3969/j.issn.1009-0185.2011.01.017 
[7] Malenovic-Nikolic, J., Vasovic, D., Janackovic, G., Milosevic, L., Krstic, I.I. (2018). Realisation of the goals of sustainable development based on application of energy indicators in environmental engineering. Journal of Environmental Protection and Ecology, 19(1): 216225.

[8] Karagiorgas, M., Tsoutsos, T., Drosou, V., Pouffary, S., Pagano, T., Lara, G.L., Mendes, J.M.M. (2006). HOTRES: Renewable energies in the hotels. An extensive technical tool for the hotel industry. Renewable and Sustainable Energy Reviews, 10(3): 198-224. https://doi.org/10.1016/j.rser.2004.09.012

[9] Chaithanakulwat, A. (2019). Design of solar-powered aeration system for shrimp ponds of farmers in Thailand. European Journal of Electrical Engineering, 21(6): 539546. https://doi.org/10.18280/ejee. 210608

[10] Benramdane, M., Abboudi, S., Ghernaout, M. (2019). Contribution to the simulation and parametric analysis of the operation of a solar concentration thermal installation. International Journal of Heat and Technology, 37(2): 446-456. https://doi.org/10.18280/ijht.370210

[11] Guellai, F., Labed, A., Moummi, N., Mahboub, C. (2019). Measurement and analysis of thermal-hydraulic performance of curved and plate flat solar air heaters; a comparative study. Instrumentation Mesure Métrologie, 18(6): 553-558. https://doi.org/10.18280/i2m.180606

[12] Charalambides, J., Wright, J. (2013). Effect of early solar energy gain according to building size, building openings, aspect ratio, solar azimuth, and latitude. Journal of Architectural Engineering, 19(3): 209-216. https://doi.org/10.1061/(ASCE)AE.1943-5568.0000129
[13] Wang, J.H., Gong, Z.R. (2011). Optimal selection of solar energy and heat pump for hot water. Water \& Waste Water Information, (2): 8.

[14] Dintchev, O.D. (2002). Solar water heater heating as an instrument for global action of climate change. Mitigation and Adaptation Strategies for Global Change, 7: 140.

[15] Ding, X.X. (2013). Research on the integration of solar hot water system and building in Changsha. Hunan University, (2): 20.

[16] Rasekh, A., Farzaneh-Gord, M. (2012). Novel theoretical approach on exergy and energy performance assessment of cylindrical solar water heater. Journal of Energy Engineering, 138(3): 119-124. https://doi.org/10.1061/(ASCE)EY.1943-7897.0000075

[17] Sopian, K., Syahri, M., Abdullah, S., Othman, M.Y., Yatim, B. (2007). Unglazed fiberglass reinforced polyester solar water heater with integrated storage system. Journal of Energy Engineering, 133(1): 26-31. https://doi.org/10.1061/(ASCE)07339402(2007)133:1(26)

[18] Zhang, C., Huang, W., Zheng X.F. (2010). The integrated design of solar water heating system for highrise housing: taking the 'Yuqin Wan of Jing Cheng' residence as an example. Huazhong Architecture, 28(4): 75.

[19] Li, G., Qiao, Q. (2014). Application of solar heating system in a building. In ICCREM 2014: Smart Construction and Management in the Context of New Technology, pp. 176-181. 